\title{
Marcador de DNA Mitocondrial para Estudos Genético-Populacionais de Tartaruga-da-amazônia (Podocnemis expansa Schweigger, 1812)
}

\author{
Maria Augusta Paes Agostini1,2, Bárbara Beatriz de Sousa Rocha ${ }^{3}$, Rafael Antônio Machado Balestra \& Samuel Rezende Paiva ${ }^{5}$
}

Recebido em 30/03/2021 - Aceito em 10/04/2021

1 Programa de Pós-Graduação em Biodiversidade e Biotecnologia da Amazônia Legal/BIONORTE, Av. Carvalho Leal, 177, Manaus/AM, Brasil. CEP: 69.065-001. <agostinimap@gmail.com>.

2 Centro de Estudos de Quelônios da Amazônia/CEQUA, Instituto Nacional de Pesquisas da Amazônia, Avenida André Araújo, Manaus/AM, Brasil.

3 Universidade de Brasilia/UnB, Instituto de Ciências Biológicas/ICB, Brasilia/DF, Brasil. CEP: 70.040-078. <barbarasrocha@gmail.com>.

4 Instituto Chico Mendes de Conservação da Biodiversidade/ICMBio, Centro Nacional de Pesquisa e Conservação de Répteis e Anfíbios/RAN, Goiânia/GO, Brasil. CEP: 74.605-090. <rafael.balestra@icmbio.gov.br>.

5 Embrapa Recursos Genéticos e Biotecnologia/CENARGEN, Laboratório de Genética Animal/LGA, Brasília/DF, Brasil. CEP: 70.234-293. <samuel.paiva@embrapa.gov.br>.

RESUMO - Os quelônios são animais de vida longa e poucos dos seus indivíduos chegam à fase adulta. Além da baixa taxa natural de recrutamento, diversas ações antrópicas vêm dificultando a manutenção das populações desse grupo. A exploração desordenada para abastecer o comércio ilegal vem se mostrando a mais danosa, principalmente em Podocnemis expansa, por ser uma espécie bastante apreciada na culinária amazônica, e muito vulnerável no período reprodutivo, época de maior captura. Seu histórico de exploração causou desequilíbrio populacional em diversas localidades na Amazônia, como pôde ser verificado durante as quase três décadas de monitoramento em importantes sítios de desova em unidades de conservação do rio Araguaia. O presente estudo desenvolveu marcadores moleculares com o objetivo de testá-los e compará-los com primers já utilizados, além de avaliar a diversidade genética e a estruturação populacional de $P$. expansa na bacia Tocantins-Araguaia. Para isso, foi coletado tecido cutâneo de 120 espécimes amostrados em três localidades no médio e submédio rio Araguaia, comparados com sequências do DNA mitocondrial de 22 localidades. A região controle do DNA mitocondrial de P. expansa é de difícil amplificação, sendo que o par de primers de outros estudos não amplificou com o material biológico utilizado neste trabalho, mostrando a eficiência do marcador molecular confeccionado. A utilização desses primers facilitará a amostragem em campo, pois, apesar de o tecido cutâneo conferir menor quantidade de DNA extraído quando comparado ao tecido sanguíneo, sua coleta como material biológico pode ser aplicada de forma mais simples, ampla e frequente em projetos de pesquisa e programas de monitoramento e manejo de quelônios, facilitando as pesquisas genéticas com esses animais. Quanto à avaliação genética, foi caracterizada panmixia na bacia Tocantins-Araguaia e baixa diversidade genética, concordando com dados da espécie. Caso as estratégias de conservação não sejam eficientes para reverterem um provável processo de deriva genética, poderão ocorrer prejuízos populacionais significativos, notadamente quanto às questões adaptativas da espécie.

Palavras-chave: Conservação; diversidade genética; quelônios; rio Araguaia.

\section{Mitochondrial DNA Marker for Genetic-Population Studies of Amazon Turtle (Podocnemis expansa Schweigger, 1812)}

\begin{abstract}
Chelonians are long-living animals and few of their individuals reach adulthood. In addition to the low natural recruitment rate, several anthropic actions have made it difficult to maintain the populations of this group. Disordered exploitation to supply the illegal trade has been the most harmful, especially in Podocnemis expansa, because it is a species highly appreciated in Amazonian cuisine, and very vulnerable in the reproductive period, a time of greatest capture. Its history of exploitation caused a population imbalance in several locations in the Amazon, as could be seen during the almost three decades of monitoring in important spawning sites in conservation units of the Araguaia River. The present study developed molecular markers with the objective of testing and comparing them with primers already used, in addition to evaluating the genetic diversity and population structure of $P$. expansa in the Tocantins-Araguaia basin. For this, cutaneous tissue was collected from 120 specimens sampled in three localities in the middle and sub-middle Araguaia river, compared with mitochondrial DNA sequences from 22 localities. The control region of mitochondrial
\end{abstract}


DNA of $P$. expansa is difficult to amplify, and the pair of primers from other studies did not amplify with the biological material used in this work, showing the efficiency of the molecular marker made. The use of these primers will facilitate field sampling, although the use of skin tissue confers a smaller amount of DNA extracted when compared to blood tissue, their collection can be applied more widely and frequently as biological material in monitoring and management programs of chelonians, facilitating genetic research with these animals. As for genetic evaluation, panmixia was characterized in the Tocantins-Araguaia basin and low genetic diversity, agreeing with data of the species. If conservation strategies are not efficient in reversing a probable genetic drift process, significant population damage may occur, nodded ly regarding the adaptive issues of the species.

Keywords: Conservation; genetic diversity; chelonian; Araguaia river.

\section{Marcador de ADN Mitocondrial para Estudios de Población Genética de Tortugas Amazónicas (Podocnemis expansa Schweigger, 1812)}

RESUMEN - Los quelonios son animales de larga vida y pocos de sus individuos llegan a la edad adulta. Además de la baja tasa de contratación natural, varias acciones antropópicas han dificultado el mantenimiento de las poblaciones de este grupo. La explotación desordenada para abastecer el comercio ilegal ha sido la más dañina, especialmente en Podocnemis expansa, porque es una especie muy apreciada en la cocina amazónica, y muy vulnerable en el período reproductivo, un momento de mayor captura. Su historia de explotación causó un desequilibrio poblacional en varios lugares de la Amazonía, como se pudo ver durante las casi tres décadas de monitoreo en importantes sitios de desove en unidades de conservación del río Araguaia. El presente estudio desarrolló marcadores moleculares con el objetivo de probarlos y compararlos con los primers ya utilizadas, además de evaluar la diversidad genética y la estructura poblacional de P. expansa en la cuenca TocantinsAraguaia. Para ello, se recogió tejido cutáneo de 120 ejemplares muestreados en tres localidades em el medio y medio del río Araguaia, en comparación con secuencias de ADN mitocondrial de 22 localidades. La región de control del ADN mitocondrial de P. expansa es difícil de amplificar, y el par de primers de otros estudios no se amplió con el material biológico utilizado en este trabajo, mostrando la eficiencia del marcador molecular hecho. El uso de estos primers facilitará el muestreo de campo, aunque el uso de tejido cutáneo confiere una menor cantidad de ADN extraído en comparación con el tejido sanguíneo, su recolección se puede aplicar más ampliamente y con frecuencia como material biológico en programas de monitoreo y manejo de quelones, facilitando la investigación genética con estos animales. En cuanto a la evaluación genética, la panmixia se caracterizó en la cuenca TocantinsAraguaia y la baja diversidad genética, coincidiendo con los datos de la especie. Si las estrategias de conservación no son eficientes para revertir un probable proceso genético de deriva, pueden producirse daños significativos en la población, asintió con la cabeza con respecto a los problemas adaptativos de la especie.

Palabras clave: Conservación; diversidad genética; quelonios; río Araguaia.

\section{Introdução}

Embora os quelônios sejam animais de vida longa, possuem como estratégia de manutenção das espécies a produção de grande quantidade de prole. O ciclo de vida desses animais é caracterizado pela maturidade sexual tardia, alta predação de seus ovos e juvenis, além da perda de ninhos e ovos por inundação devido ao aumento do nível das águas, resultando em uma taxa de recrutamento entre $1 \%$ e $2 \%$ (Ferri, 2002; Vogt, 2008; Ferrara et al., 2017). Associadas aos fatores naturais, diversas ações antrópicas prejudicam áreas de uso, alimentação e desova de quelônios, em consequência de alterações do habitat pela construção de barragens, urbanização, queimadas, desmatamento, canalização de cursos d'água, entre outros, que podem causar impactos irreversíveis, afetando a viabilidade de suas populações (Fagundes et al., 2015; Fagundes et al., 2018; Norris et al., 2018).

Ademais, esses répteis constituem um recurso da fauna silvestre de grande importância para comunidades amazônicas que vivem às margens de rios e lagos e se alimentam de suas carnes, ovos, gordura e vísceras. Mas é o consumo esbanjado historicamente em grandes cidades, abastecido pelo comércio ilegal, que prejudica significativamente a taxa de sobrevivência e vem provocando, há séculos, um declínio acentuado de populações das espécies de quelônios cinegéticas 
na Amazônia (Balestra et al., 2016; Ferrara et al., 2017; Lacava \& Balestra, 2019).

A espécie desse grupo que mais tem sofrido com a superexploração na Amazônia é o maior quelônio de água doce da América do Sul, Podocnemis expansa, popularmente conhecida como tartaruga-da-Amazônia (Pignati \& Pezzuti, 2012; Pantoja-Lima, 2014; Andrade, 2015). Na época da desova, as fêmeas ficam extremamente vulneráveis, seus ninhos são de mais fácil reconhecimento e estão mais sujeitos às variações ambientais do que de outras espécies com diferentes estratégias de nidificação (Valenzuela et al., 1997; Ferrara et al., 2017; Eisemberg et al., 2019). Consequentemente, avaliar a estrutura genética da espécie, bem como o fluxo gênico, se torna um grande desafio, já que as populações, em geral, não se encontram geneticamente em equilíbrio (Valenzuela et al., 2001b; Pearse et al., 2006; Balestra et al., 2016).

O uso de bancos genômicos pode ser considerado estratégico para o estudo da biodiversidade por dispor dados sobre animais nativos com potencial econômico, propiciando a caracterização molecular e a determinação de parâmetros genéticos importantes para manejo $e$ conservação das espécies (Maués \& Ianella, 2016).

A região controle do DNA mitocondrial (mtDNA), a qual é responsável por toda a regulação e transcrição mitocondrial, possui altas taxas de mutação e é bastante utilizada em estudos intraespecíficos de vários grupos biológicos (Stewart \& Barker, 1994; Starkey et al., 2003), inclusive em estudos genéticopopulacionais de quelônios, principalmente com o gênero Podocnemis: P. expansa (Pearse et al., 2006; Piñeda-Catalán et al., 2012), P. unifilis (Piñeda-Catalán et al., 2012; Agostini, 2016), P. erythrocephala (Santos et al., 2016; Oliveira et al., 2019), P. sextuberculata (Viana et al., 2017; Oliveira et al., 2019) e P. lewyana (VargasRamirez, 2012). Esta porção do mtDNA de $P$. expansa contém uma repetição de minissatélites com um microssatélite inserido de tamanho variável (Pearse et al., 2006), a qual dificulta a amplificação e o sequenciamento do DNA.

O Centro Nacional de Pesquisa e Conservação de Répteis e Anfíbios (RAN) e entidades parceiras que atuam no rio Araguaia, especialmente na sua porção média e submédia, que abrange a Área de Proteção Ambiental (APA)
Meandros do rio Araguaia, Parque Nacional (PARNA) do Araguaia e a Reserva extrativista (RESEX) Lago do Cedro, implementam desde 1985 o Programa Nacional de Conservação dos Quelônios Continentais, com iniciativas de pesquisa populacional para o monitoramento $e$ manejo reprodutivo de $P$. expansa. Mas, apenas em 2009, com a formalização da parceria técnica com a Embrapa Recursos Genéticos e Biotecnologia (CENARGEN) essas entidades começaram a contemplar estudos sobre estrutura genética de quelônios na região, promovendo o avanço de diversos estudos como o desenvolvimento de marcadores moleculares para resolução de incertezas taxonômicas e identificação de unidades conservativas intraespecíficas, além do uso forense em animais caçados e comercializados ilegalmente, permitindo atribuir aos indivíduos, população ou linhagem, uma região específica de origem (Arif et al., 2011; Iyengar, 2014).

Dado o relevante papel de $P$. expansa nos sistemas ecológicos que integra, além do potencial de uso da espécie em sistemas de criação in situ e ex situ (Balestra et al., 2016), este trabalho objetivou desenvolver e testar a eficiência de um marcador molecular baseado em polimorfismos do DNA extraído através de tecido cutâneo, incorporando novas ferramentas de aferição de viabilidade populacional; e avaliar a diversidade genética, verificando a presença ou não de estrutura genética em três localidades monitoradas, representando a abrangência da região na bacia Tocantins-Araguaia em relação à outras regiões da Amazônia.

\section{Materias e Métodos}

\section{Área de estudo}

Com uma extensão total de 2.114 quilômetros, o rio Araguaia nasce nos municípios de Mineiros, em Goiás, e Alto Taquari, no Mato Grosso, na Serra do Caiapó, próximo ao Parque Nacional das Emas, e forma a divisa natural entre Goiás, Mato Grosso, Tocantins e Pará. Compreende uma das principais bacias hidrográficas do CentroOeste, a Tocantins-Araguaia. Em seu percurso, seus meandros delimitam, juntamente com os do rio Javaés, a maior ilha fluvial do mundo, a ilha do Bananal, onde estão localizados o Parque Nacional do Araguaia e o Parque Indígena do Araguaia (Aquino et al., 2009; Navarro, 2013). 

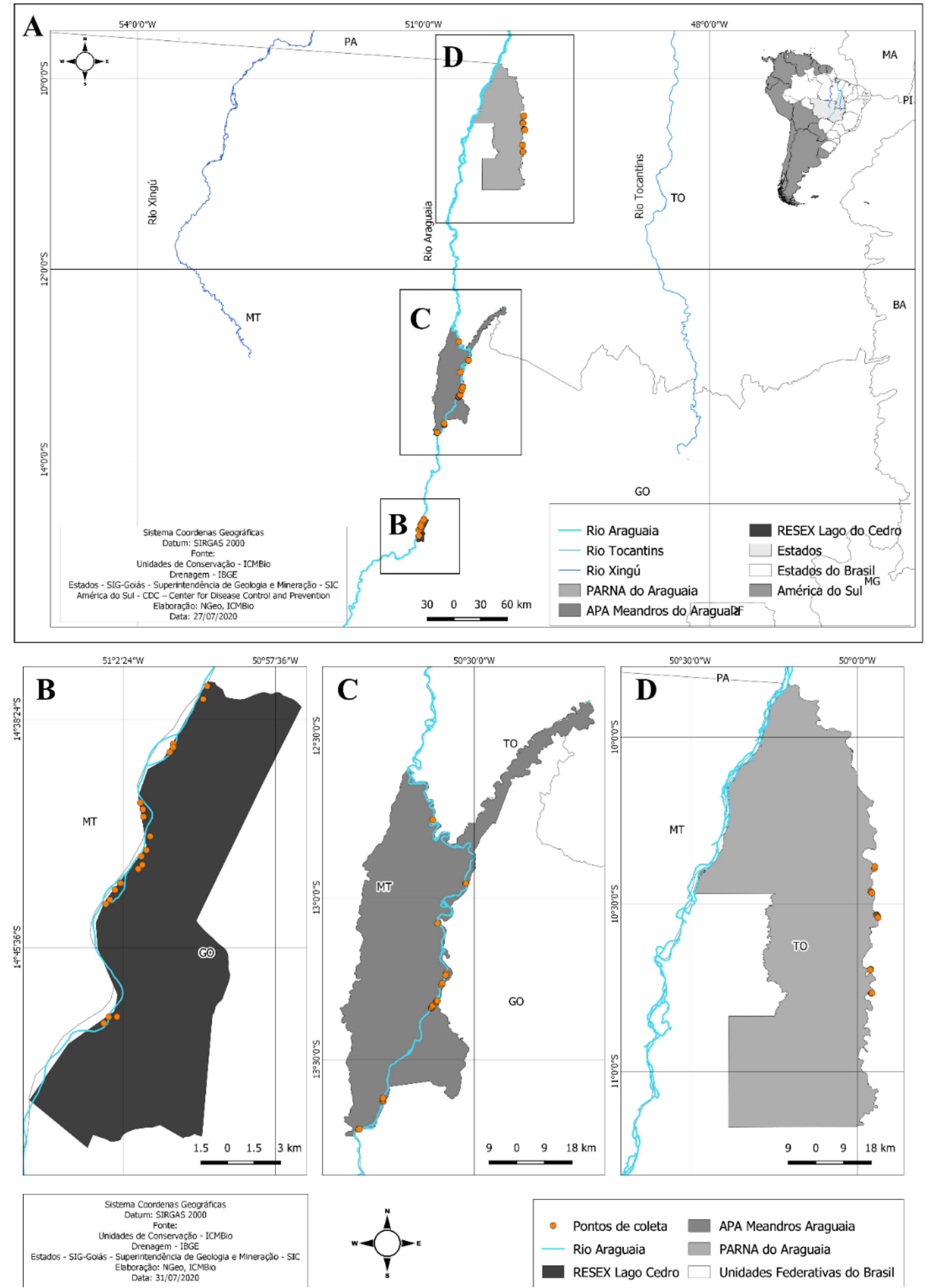

Figura 1 - Mapa da região amostral (A) indicando os sítios de reprodução de P. expansa monitorados na região do médio e submédio rio Araguaia, nas divisas dos estados de Goiás, Mato Grosso e Tocantins, destacando as três regiões de coleta de amostras biológicas do presente estudo: (B) Reserva Extrativista (RESEX) Lago do Cedro; (C) Área de Proteção Ambiental (APA) Meandros do rio Araguaia; e (D) Parque Nacional (PARNA) do Araguaia. 
Os sítios amostrados (bancos de areia praias) estão distribuídos ao longo de cerca de $480 \mathrm{~km}$ aquaviários, compreendendo 20 pontos de coleta no interior da RESEX Lago do Cedro (Figura 1B), nove pontos de coleta no interior da APA Meandros do rio Araguaia (Figura 1C) $e$ oito pontos de coleta no interior do PARNA do Araguaia (Figura 1D), nas divisas dos estados de Goiás, Mato Grosso e Tocantins.

A região que abrange essas unidades de conservação (Figura 1A) é caracterizada por fitofisionomias típicas do ecótone cerradoamazônico, com predominância de formações vegetais do bioma Cerrado, abrigando matas ciliares nas margens do rio Araguaia, bem como parque de cerrado e cerradão em trechos mais distantes do rio, além de áreas antropizadas formadas por pastagens e lavouras circundantes às áreas protegidas (Santos et al., 2008).

O clima da região é definido como Aw (tropical de verão úmido e período de estiagem no inverno), segundo a classificação climática Köppen-Geiger. Comporta duas estações bem definidas: a chuvosa e a seca, que controlam as variações da descarga no Araguaia. A estação chuvosa ocorre entre novembro e abril, enquanto a estação seca se estende de maio a outubro (Aquino et al., 2009). Na estação seca, entre os meses de agosto e setembro, ocorre o processo de nidificação de $P$. expansa nessa região, com as primeiras emergências de filhotes dos ninhos ao final de outubro, estendendo-se até dezembro, já no período chuvoso (Lacava \& Balestra, 2019).

\section{Coleta do material biológico}

Este estudo foi autorizado pelo Instituto Chico Mendes de Conservação da Biodiversidade (ICMBio) através da autorização SISBIO no 13447/2009. Foram amostrados 120 indivíduos de $P$. expansa em 37 sítios de desova (praias - bancos arenosos) nas regiões do médio e submédio rio Araguaia, compreendendo 30 indivíduos adultos e 10 filhotes em cada uma das três unidades de conservação monitoradas (Figura 1A), no período de nidificação da estação reprodutiva da espécie nessa região no ano de 2009, entre os meses de setembro e novembro.

Foram coletadas pequenas amostras de tecido cutâneo, na expansão de pele distal (lateral) da pata dianteira característico da espécie, área pouco vascularizada, em filhotes recém-nascidos (Figura 2) e nas matrizes (fêmeas adultas) de $P$. expansa capturadas pelo método da viração, ou seja, busca ativa com captura manual e retenção do espécime posicionado em decúbito dorsal (Balestra et al., 2016), logo após a desova. Após as coletas, as fêmeas adultas e os filhotes amostrados foram soltos no rio em seus locais de captura (ou nascimento).

Para a coleta de tecido, foi utilizado tesoura esterilizada, solução de álcool $70 \%$ inicialmente $e$ iodo posteriormente para desinfecção da área afetada (Figura 2A e B). As amostras foram estocadas em álcool $96 \%$ e destinadas para processamento no Laboratório de Genética Animal (LGA) do CENARGEN em Brasília, no Distrito Federal, Instituição Fiel Depositária do Patrimônio Genético Nacional.

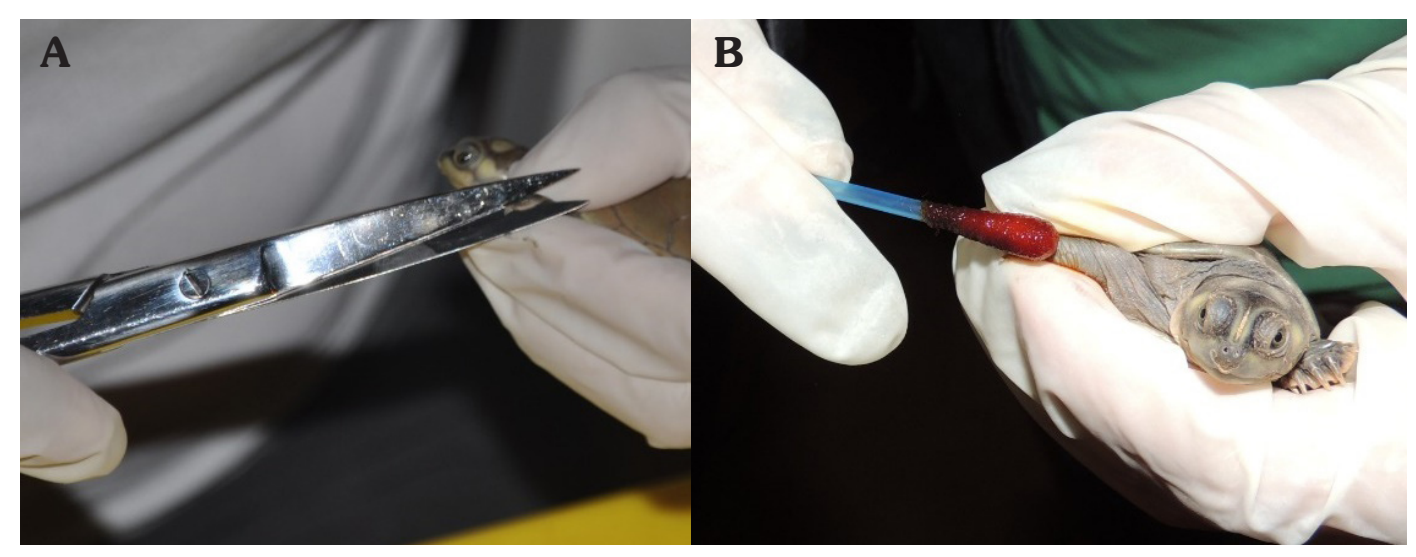

Figura 2 - Coleta de tecido cutâneo (A) e desinfecção com solução de álcool e iodo (B) em filhote de P. expansa na APA Meandros do rio Araguaia. Crédito: Ana Paula Gomes Lustosa. 


\section{Extração e amplificação do DNA via reação em cadeia da polimerase (PCR)}

O DNA total das amostras foi extraído utilizando o "DNeasy Blood \& Tissue Kit" da Qiagen seguindo as recomendações do fabricante; foram quantificadas através de espectrofotometria, $e$ qualificadas em eletroforese em gel de agarose $1 \%$ corado com brometo de etídeo. As amostras de DNA total amplificadas por PCR (Innis et al., 1990) foram testadas com dois pares de primers de fragmentos da alça $D$-Loop da Região Controle do DNA mitocondrial (mtDNA), utilizada em diversos trabalhos do gênero Podocnemis (Pearse et al., 2006; Vargas-Ramirez, 2012; Piñeda-Catalán et al., 2012; Agostini, 2016; Santos et al., 2016; Viana et al., 2017; Oliveira et al., 2019).

Para incorporar novas ferramentas de aferição de viabilidade populacional em $P$. expansa, foram utilizadas seis amostras nos primeiros testes seguindo os padrões de PCR de outros autores; empregou-se inicialmente 50ng de DNA, $1 \mathrm{pMol}$ de cada primer, $4 \mathrm{mM}$ de $\mathrm{MgCl}_{2}, 0,8 \mathrm{mM}$ dNTPs, 1,5 U da enzima Taq DNA polimerase e 1,5x do tampão da enzima, completando com água para um volume final de $15 \mu \mathrm{L}$ (Viana et al., 2017). Foi utilizado o par de primers $\mathrm{PRO}$ (5'-CCCATCACCCACTCCCAAAGC-3') (Pearse et al., 2006) e 12SR5 (5'-GTCAGGACCATGCCTTTGTG-3') (Kocher et al., 1989), já referenciado em outros estudos; e o par desenhado pela equipe do LGA, mesmo local em que foi realizado o sequenciamento das amostras do presente estudo: CR-F (5'-AACTCCCATCACCTA CTCCCAAAG-3') eCR-R(5'-TGAACCAGAATGTCCAGCCTCTCA-3').

\section{Análise dos dados}

Para verificar a abrangência da região da bacia Tocantins-Araguaia em relação a outras regiões da Amazônia, foram acrescentadas 294 sequências do GenBank (http://www.ncbi.nlm.nih. gov) da região controle do mtDNA de $P$. expansa de 22 localidades (Tabela 1S) de Pearse et al. (2006), sendo elas provenientes das bacias dos rios Orinoco (Venezuela), Amazonas (rios Branco, Purus, Guaporé, Uatumã, Amazonas, Trombetas, Tapajós e Xingu), Araguaia (PARNA do Araguaia e rio das Mortes), além de algumas com localização específica não informada. Todas as sequências foram alinhadas e editadas com o programa MEGA v.5.0 (Kumar et al., 2008) a partir da sequência de referência [DQ352804]. Realizou- se análise de network com o modelo de Median Joining - MJ (Bandelt et al., 1999) pelo método de vetores medianos através do software Network 4.1.1.2 (www.fluxus-engineering.com, acessado em junho 2010).

Para estimar a distribuição dos haplótipos, foi utilizado o software DNAsp v5 (Librado \& Rozas, 2009), assim como os principais parâmetros de diversidade como o número de haplótipos (Nh), número de sítios segregantes (S), diversidade nucleotídica $(\pi)$ e diversidade haplotípica $(\mathrm{Hd})$.

\section{Resultados}

Ao serem testados os primers utilizados em outros trabalhos (PRO e 12SR5) com as condições de PCR baseadas em trabalhos com DNA extraído de tecido sanguíneo (Piñeda-Catalán et al., 2012; Vargas-Ramirez, 2012; Agostini, 2016; Santos et al., 2016; Viana et al., 2017; Michels \& Vargas-Ramirez, 2018), as amostras não foram amplificadas com variações das concentrações dos reagentes nem das condições de ciclagem e, com isso, testaram-se os dois pares de primers com o kit "Qiagen Master Mix" de PCR, e as amostras amplificaram somente com os primers CR-F e CR-R, evidenciando a eficiência dos marcadores desenvolvidos no presente trabalho.

Sendo assim, houve sucesso no sequenciamento de 69 amostras com 519 pares de bases (pb) cada, que foram comparadas com os $492 \mathrm{pb}$ das 294 sequências do GenBank de 22 localidades na bacia amazônica (Tabela 1S), totalizando 25 localidades e 363 indivíduos amostrados. A $\pi$ (diversidade nucleotídica) total foi 0,0023 e a Hd (diversidade haplotípica) de 0,519. Nenhum polimorfismo foi identificado entre as três localidades coletadas ( $\mathrm{Nh}=1, \mathrm{~S}=0$ ), mas quando foram analisadas todas as sequências, verificou-se oito $(\mathrm{Nh})$ haplótipos diferenciados por oito polimorfismos (S) de um único nucleotídeo (Single Nucleotide Polymorphism - SNP).

A análise de Network obtida a partir do modelo de Median Joining (Figura 3) mostra os oito haplótipos encontrados. $\mathrm{O}$ mais frequente (H3) possui 180 indivíduos de sequências do banco de dados e das três localidades do presente estudo; e o segundo haplótipo mais frequente (H1), com 164 provenientes dos rios Branco (RR), Purus (AM), Amazonas (AM), Tapajós (PA) e Xingu (PA), além da própria bacia Tocantins-Araguaia. 


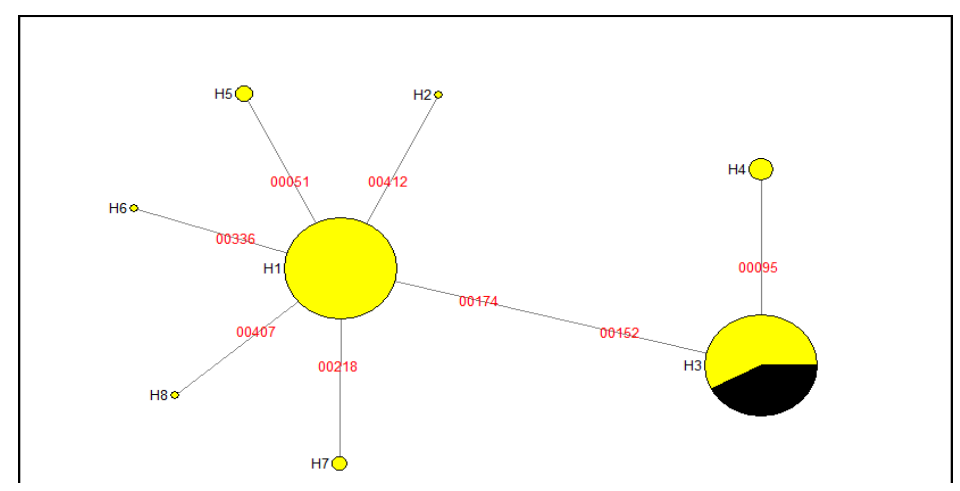

Figura 3 - Análise de Network (Median Joining) de 25 localidades de ocorrência de P. expansa.

*Em negro estão destacados os animais sequenciados no presente estudo.

\section{Discussão}

A escolha do material biológico para extração do DNA é um fator muito importante em estudos genéticos, por influenciar na quantidade e qualidade do DNA total obtido. Pesquisas com quelônios utilizam desde sangue a tecidos do fígado, músculos, pedaços de casco (Quadro 1S), podendo ser invasivos e até letais (Bezerra et al., 2013). O material biológico mais utilizado para esse fim é o tecido sanguíneo (Viana et al., 2017; Michels \& Vargas-Ramirez, 2018), que, em geral, quando realizado por quem tem a devida perícia, não prejudica a saúde do espécime amostrado, o que requer prática para localizar determinados vasos sanguíneos que são, proporcionalmente às dimensões corporais desses animais, delgados $e$ profundos (McArthur et al., 2004; Mader, 2006; Balestra et al., 2016).

Neste trabalho, foram utilizadas amostras de tecido cutâneo e, muito embora tenha-se obtido uma quantidade de DNA extraído menor do que poderia ter sido alcançado através de amostras de tecido sanguíneo, logrou-se êxito na amplificação das amostras de DNA. Com isso, a utilização do marcador molecular desenvolvido neste estudo tem grande potencial de ampliar $e$ intensificar coletas de campo de amostras para estudos genéticos, especialmente em programas de monitoramento e manejo de espécies de quelônios amazônicos, pela facilidade de coleta, preservação, estocagem, baixo custo com recursos materiais e baixo risco de morbidez e mortalidade aos espécimes manipulados (Balestra, 2016; Balestra et al., 2016; Lacava \& Balestra, 2019).
A eficiência dos primers desenvolvidos na amplificação do DNA no presente estudo ficou evidente no tamanho do fragmento obtido de $519 \mathrm{pb}$, haja vista que outros trabalhos que utilizaram somente um par de primer obtiveram entre 508 pb a 691 pb, e os que utilizaram dois pares obtiveram de $630 \mathrm{pb}$ (P. unifilis) a $1120 \mathrm{pb}$ e $1343 \mathrm{pb}$ (P. expansa) (Quadro 1S), indicando a dificuldade de amplificação da Região Controle mtDNA para $P$. expansa com apenas um par de primer. Portanto, sugere-se que esse marcador molecular seja testado também em outras espécies do gênero Podocnemis que não possuem regiões que dificultam a amplificação da alça $D$-loop do mtDNA (Vargas-Ramirez, 2012; Santos et al., 2016; Viana et al., 2017).

Os parâmetros genéticos de diversidade haplotípica (Hd) e diversidade nucleotídica $(\pi)$ da região controle do DNAmt podem ser úteis para saber o estado atual da população de uma determinada espécie (Bandelt et al., 1999). A análise de Network obtida a partir do modelo de Median Joining, método que viabiliza a caracterização filogenética a partir de dados intraespecíficos, com pequenas distâncias genéticas entre indivíduos (Bandelt et al., 1999; Kong et al., 2015), mostrou que o haplótipo H3 foi o mais abundante da amostragem total (Figura 3 ), o que pode ser explicado pelo maior número de sequências amostradas coletadas nas localidades 1,2 e 3 no presente estudo (Tabela 1S). O segundo mais frequente, H1 (Figura 3) evidenciou ser um haplótipo ancestral devido ao padrão em formato de "estrela", e corrobora com o grupo descrito por Pearse et al. (2006) como Cluster Amazon, originário da calha do sistema Solimões-Amazonas, com localidades distribuídas desde a drenagem do Peru até o baixo rio Tapajós, com baixa diferenciação genética. 
A região monitorada no médio e submédio rio Araguaia representa uma expressiva amostragem da bacia Tocantins-Araguaia com quase 500 quilômetros de trecho do rio Araguaia. A ausência de polimorfismo encontrada no haplótipo entre as localidades deste estudo indica falta de estrutura populacional - panmixia, sugerindo homogeneidade gênica entre os indivíduos de $P$. expansa. Portanto, é possível que não exista ou há uma baixa quantidade de barreiras geográficas naturais ou artificiais entre os pontos amostrados, que ainda não afetaram a região controle do mtDNA, levando em consideração o tempo de geração e a taxa mutacional da espécie (Martin \& Palumbi, 1993).

Entretanto, é necessário avaliar se existem barreiras à dispersão e à migração de $P$. expansa ao longo de sua distribuição, analisando outras localidades dentro e fora do sistema hidrológico Tocantins-Araguaia. Essda ponderação se enaltece quando se considera que as barreiras geográficas naturais, como as corredeiras e cachoeiras da bacia Tocantins-Araguaia, foram evidenciadas como causa da diferenciação de populações de $P$. unifilis (Agostini, 2016), e diferenças geológicas entre esta bacia e a do rio Amazonas causaram a separação de outras espécies aquáticas, como botos (Hrbek et al., 2014) e peixes (Amaral et al., 2013).

A panmixia observada entre as localidades amostradas apresenta nível de estruturação populacionalpadrãodentrodecadabaciahidrográfica, e corrobora com resultados de Pearse et al. (2006). Neste estudo, que descreve as demais sequências genéticas utilizadas, foi também verificado que, no contexto de sub-bacia hidrográfica, a estruturação condiz com as características da espécie, e ambos os sexos frequentemente retornam às mesmas ou a próximas regióes para copular e nidificar (Valenzuela, 2001b; Pearse et al., 2006; Vogt, 2008).

Os dados desta pesquisa subsidiarão a análise comparativa entre as localidades amostradas com outras regiões da bacia Tocantins-Araguaia, assim como de outras bacias hidrográficas, no sentido de avaliar o fluxo gênico e a saúde genética da espécie. Com os primers desenvolvidos poderão ser realizados trabalhos no intuito de inferir se, por exemplo, uma suspeita redução no número de desovas está relacionado à possível diminuição da variabilidade genética na região e ao desequilíbrio populacional, principalmente comparando com marcadores moleculares biparentais (Agostini, 2016) como microssatélites e genômica populacional.

Tendo em vista a baixa diversidade genética, é pertinente recomendar a ampliação e intensificação de ações de proteção e manejo visando o revigoramento populacional de $P$. expansa na bacia Tocantins-Araguaia, como forma de mitigar um possível processo de deriva genética, que pode causar danos irreversíveis caso o número efetivo populacional seja baixo, influenciando principalmente nas questões adaptativas da espécie (Frankham et al., 2008).

\section{Conclusões}

O presente estudo desenvolveu $e$ comprovou a eficácia de um novo marcador molecular que poderá ser utilizado em $P$. expansa e em outras espécies do gênero a serem testadas, $e$, principalmente, se mostrou eficiente na utilização de materiais biológicos com relativa baixa quantidade de DNA, facilitando as coletas de amostras em atividades de campo. Verificou-se baixa diversidade genética, assim como a ausência de estrutura populacional na bacia Tocantins-Araguaia, corroborando com dados ecológicos e genéticos da espécie.

\section{Agradecimentos}

Ao Programa Pibic/ICMBio (Edição 2012), pelo suporte financeiro através da concessão da bolsa de apoio a pesquisa que viabilizou a realização deste trabalho. Ao Centro Nacional de Pesquisa e Conservação de Répteis e Anfíbios (RAN) pela proposição deste trabalho, pela coleta das amostras biológicas e supervisão técnica para o desenvolvimento da pesquisa. À Embrapa Recursos Genéticos e Biotecnologia (CENARGEN), pela disponibilização do Laboratório de Genética Animal (LGA/Embrapa) e dos recursos materiais usados neste trabalho, e, em especial, pelo apoio técnico do Dr. Samuel Rezende Paiva, pesquisador responsável pelo LGA, com as análises genético-moleculares.

\section{Referências}

Agostini MAP. 2016. Padrões genético-populacionais do "tracajá" Podocnemis unifilis (Troschel, 1848) (TESTUDINES: PODOCNEMIDIDAE) na Amazônia brasileira. Dissertação (Mestrado em Diversidade Biológica). Universidade Federal do Amazonas. 40p. 
Amaral CRL, Brito P M, Silva DA \& Carvalho EF. 2013. A new cryptic species of South American freshwater pufferfish of the genus Colomesus (Tetraodontidae), based on both morphology and DNA data. PLoS One, 8(9): e74397.

Andrade PCM. 2015. Manejo Comunitário de Quelônios (Família Podocnemididae - Podocemis unifilis, P. sextuberculata, P.expansa, P.erythrocephala) no médio rio Amazonas e Juruá. Tese de Doutorado BADPI/INPA, Manaus. 336p.

Aquino SS, Latrubesse EM \& Souza-Filho EE. 2009. Caracterização Hidrológica e Geomorfológica dos Afluentes da Bacia do Rio Araguaia. Revista Brasileira de Geomorfologia, 10(1): 43-54.

Arif IA et al. 2011. DNA marker technology for wildlife conservation. Saudi J Biol Sci., 18: 219-225.

Balestra RAM (Org.). 2016. Manejo conservacionista e monitoramento populacional de quelônios amazônicos. $1^{\mathrm{a}}$ ed. CNI - Centro Nacional de Monitoramento e Informações Ambientais, Brasília: Ibama, 137p.

Balestra RAM et al. 2016. Roteiro para inventários e monitoramentos de quelônios continentais. Biodiversidade Brasileira, 1: 114-152.

Bandelt HJ, Forster P \& Röhl A. 1999. Median-joining networks for inferring intraspecific phylogenies. Mol Biol Evol. Jan; 16(1): 37-48. doi: 10.1093/oxfordjournals. molbev.a026036. PMID: 10331250.

Bezerra MF, Lacerda LD, Lima EHSM \& Melo MTD. 2013. Monitoring mercury in green sea turtles using keratinized carapace fragments (scutes). Marine pollution Bulletin. 77(1-2): 424-427.

Eisemberg CC, Vogt RC, Balestra RAM, Reynolds SJ \& Christian KA. 2019. Don't put all eggs in one basket Lessons learned from the largest scale and longest-term wildlife conservation program in the Amazon Basin. Biol Conserv. 238: 108182.

Fagundes CK, Vogt RC \& De Marco Jr P. 2015. Testing the efficiency of protected areas in the Amazon for conserving freshwater turtles. Divers Distrib. 22(2): 123-135.

Fagundes CK, Vogt RC, de Souza RA \& De Marco Jr P. 2018. Vulnerability of turtles to deforestation in the Brazilian Amazon: indicating priority areas for conservation. Biol. Conserv. 226: 300-310.

Ferrara C, Fagundes CK, Morcatty T \& Vogt RC. 2017. Quelônios Amazônicos: Guia de identificação e distribuição. Manaus, Brazil: Wildlife Conservation Society Brasil. 280p.

Ferri V. 2002. Turtles \& Tortoises: A Firefly Guide. Firefly Books. 256p.
Frankham R, Ballou JD \& Briscoe DA. 2008. Fundamentos de Genética da Conservação. Ribeirão Preto/SP, SBG (Sociedade Brasileira de Genética). 229 p.

Hrbek T, da Silva VMF, Dutra N, Gravena W, Martin AR \& Farias IP. 2014. A new species of river dolphin from Brazil or: how little do we know our biodiversity? PLoS One. 9(1): e83623.

Hrbek T \& Farias IP. 2008. The complete mitochondrial genome of the pirarucu (Arapaima gigas, Arapaimidae, Osteoglossiformes). Genetics and Molecular Biology. Journal Article. 31(1, Suppl.): 293-302.

Innis MA, Gelfand DH, Sninsky JJ \& White TJ. 1990. PCR Protocols: A Guide to Methods and Applications. Academic Press, San Diego, CA. 482p.

Iyengar A. 2014. Forensic DNA analysis for animal protection and biodiversity conservation: a review. J Nat Conserv., 22: 195-205.

Kocher TD et al. 1989. Dynamics of mitochondrial DNA evolution in animals: amplification and sequencing with conserved primers. Proc. Natl. Acad. Sci., USA, 86: 6196-6200.

Kong S, Sánchez-Pacheco S \& Murphy R. 2015. On the use of median-joining networks in evolutionary biology. Cladistics. 32. n/a-n/a. 10.1111/cla.12147.

Kumar S, Dudley J, Neim M \& Tamura K. 2008. Mega: A biologist-centric software for evolutionary analysis of DNA and protein sequences. Briefings in Bioinformatics, 9: 299-306.

Lacava RV \& Balestra RAM (Orgs.). 2019. Plano de Ação Nacional para Conservação dos Quelônios Amazônicos. CNI - Centro Nacional de Monitoramento e Informações Ambientais, Brasília: Ibama, 192p.

Librado P \& Rozas J. Dna SP. 2009. V5: A software for comprehensive analysis of DNA polymorphism data. Bioinformatics, 25: 1451-1452.

Mader DR (ed). 2006. Reptile Medicine and Surgery, 2nd ed.: Elsevier. St. Louis.

McArthur S, Wilkinson R \& Meyer J (eds.). 2004. Medicine and Surgery of Turtles and Tortoises.: Blackwell Science Ltd. Cambridge, MA.

Martin AP \& Palumbi SR. 1993. Body size, metabolic rate, generation time, and the molecular clock. Proceedings of the National Academy of Sciences, 90(9): 4087-4091.

Maués MS \& Ianella P. 2016. Inventário de Recursos Genéticos Animais da Embrapa. Editores técnicos. Embrapa. Brasília, DF. 108p. 
Michels J \& Vargas-Ramirez M. 2018. Red-headed Amazon River Turtles in Venezuela and Colombia: population separation and connection along the famous route of Alexander von Humboldt. Zoology, 130: 67-78.

Navarro EA. 2013. Dicionário de tupi antigo: a língua indígena clássica do Brasil. São Paulo. Global. 544p.

Norris D, Michalski F \& Gibbs JP. 2018. Beyond harm's reach? Submersion of river turtle nesting areas and implications for restoration actions after Amazon hydropower development. PeerJ, 6: e4228.

Oliveira JA, Farias IP, Costa GC \& Werneck FP. 2019. Model-based riverscape genetics: disentangling the roles of local and connectivity factors in shaping spatial genetic patterns of two Amazonian turtles with different dispersal abilities. Evolutionary Ecology, 33: 273-298.

Pantoja-Lima J, Aride PHR, Oliveira AT, FelixSilva D, Pezzuti JCB \& Rebêlo GH. 2014. Chain of commercialization of Podocnemis spp. turtles (Testudines: Podocnemididae) in the Purus River, Amazon basin, Brazil: current status and perspectives. Journal of Ethnobiology and Ethnomedicine, 10: 8.

Pearse DE, Arndt AD, Valenzuela N, Miller BA, Cantarelli VH \& Sites JW. 2006 Estimating population structure under non-equilibrium conditions in a conservation context: continent- wide population genetics of the giant Amazon river turtle Podocnemis expansa (Chelonia, Podocnemidae). Molecular Ecology, 15: 985-1006.

Pignati MT \& Pezzuti JCB. 2012. Alometria reprodutiva de Podocnemis unifilis (Testudines: Podocnemididae) na várzea do baixo rio Amazonas, Santarém, Pará, Brasil. Iheringia, Sér. Zool., 102(1): 48-55.

Pineda-Catalan O et al. 2012. Conservation genetics of harvested river turtles, Podocnemis expansa and Podocnemis unifilis, in the Peruvian Amazon: All roads lead to Iquitos. Mitochondrial DNA, 23(3): 230-238.

Santos FJM, Luz VLF, Peña AP, Júnior SGF \& Pires RAP. 2008. Relação dos Squamata (Reptilia) da Área de Proteção Ambiental Meandros do Rio Araguaia, Brasil. Goiânia, 35(3): 401-407.

Santos RC et al. 2016. Testing the Effects of Barriers on the Genetic Connectivity in Podocnemis erythrocephala (Red-Headed Amazon River Turtle): Implications for Management and Conservation. Chelonian Conservation and Biology, 15(1): 12-22.

Starkey DE et al. 2003. Molecular systematics, phylogeography, and the effects of Pleistocene glaciation in the painted turtle (Chrysemys picta) complex. Evolution, 57: 119-128.
Stewart DT \& Baker AJ. 1994. Evolution of mtDNA Dloop sequences and their use in phylogenetic studies of shrews in the subgenus Otrisorex (Sorex: Soricidae: Insectivora). Molecular Phylogenetics and Evolution, 3: 38-46.

Turtle Taxonomy Working Group [Rhodin AGJ et al.]. 2017. Turtles of the World: Annotated Checklist and Atlas of Taxonomy, Synonymy, Distribution, and Conservation Status (8th Ed.). In: Rhodin AGJ et al. (eds.). Conservation Biology of Freshwater Turtles and Tortoises: A Compilation Project of the IUCN/ SSC Tortoise and Freshwater Turtle Specialist Group. 8 ed. Chelonian Research Monographs, 7: 1-292. doi: 10.3854/crm.7.checklist.atlas.v8.2017.

Valenzuela N, Botero R \& Martinez E. 1997. Field study of sex determination in Podocnemis expansa from Colombian Amazonia. Herpetologica, 53(3): 390-398.

Valenzuela N. 2001a. Maternal effects on life-history traits in the Amazonian giant river turtle Podocnemis expansa. Journal of Herpetology, Athens, 35(3): 368-378.

Valenzuela N. 2001b. Genetic differentiation among nesting beaches in the highly migratory giant river turtle (Podocnemis expansa) from Colombia. Herpetologica, 57: 48-57.

Vanzolini PE. 1967. Notes on the nesting behaviour of Podocnemis expansa in the Amazon Valley (Testudines, Pelomedusidae). Papéis Avulsos de Zoologia, 20: 191-215.

Vanzolini PE. 2003. On clutch size and hatching success of the South American turtles Podocnemis expansa (Schweigger, 1812) and P. unifilis Troschel, 1848 (Testudines, Podocnemididae). Anais da Academia Brasileira de Ciências 75(4): 415-430.

Vargas-Ramírez M, Castaño-Mora OV \& Fritz U. 2008. Molecular phylogeny and divergence times of ancient South American and Malagasy river turtles (Testudines: Pleurodira: Podocnemididae). Org. Divers. Evol., 8: 388-398.

Vargas-Ramírez M, Stuckas H, Castanõ-Mora OV \& Fritz U. 2012. Extremely low genetic diversity and weak population differentiation in the endangered Colombian river turtle Podocnemis lewyana (Testudines: Podocnemididae). Conserv Genet., 13: 65-77.

Viana MNS et al. 2017. Population genetic structure of the threatened Amazon River turtle Podocnemis sextuberculata (Testudines, Podocnemididae). Chelonian Conserv Biol., 16(2): 128-138.

Vogt RC. 2008. Tartarugas da Amazônia. Wust Ediciones, Lima. 104p. 


\section{Material Suplementar (S1)}

Tabela 1S - Sequências e localidades utilizadas no presente estudo.

\begin{tabular}{|c|c|c|c|c|}
\hline Localidade & $\begin{array}{c}\text { Número de acesso nos bancos } \\
\text { de dados }\end{array}$ & $\begin{array}{c}\text { Bacia hidrográfica/ } \\
\text { País }\end{array}$ & Rio/ Ponto de Coleta & Referência \\
\hline 1 & A serem depositadas & Tocantins-Araguaia/Brasil & $\begin{array}{l}\text { Araguaia/ APA Meandros do rio } \\
\text { Araguaia }\end{array}$ & Presente estudo \\
\hline 2 & A serem depositadas & Tocantins-Araguaia/Brasil & Araguaia/ RESEX Lago do Cedro & Presente estudo \\
\hline 3 & A serem depositadas & Tocantins-Araguaia/Brasil & Araguaia/ PARNA do Araguaia & Presente estudo \\
\hline 4 & $\begin{array}{l}\text { DQ352804; DQ352803; DQ352802; } \\
\text { DQ352801; DQ352800; DQ352799; } \\
\text { DQ352798; DQ352797; DQ352796; } \\
\text { DQ352795; DQ352794; DQ352793; } \\
\text { DQ352792; DQ352791; DQ352790; } \\
\text { DQ352789; DQ352788; DQ352787 }\end{array}$ & Orinoco/Venezuela & Orinoco & Pearse et al., 2006 \\
\hline 5 & $\begin{array}{l}\text { DQ352786; DQ352785; DQ352784; } \\
\text { DQ352783; DQ352782; DQ352781; } \\
\text { DQ352780; DQ352779; DQ352778; } \\
\text { DQ352777; DQ352776; DQ352775; } \\
\text { DQ352774; DQ352773; DQ352772; } \\
\text { DQ352771; DQ352770; DQ352769; } \\
\text { DQ352768; DQ352767; DQ352766; } \\
\text { DQ352765; DQ352764; DQ352763 }\end{array}$ & Amazônica/Brasil & Branco & Pearse et al., 2006 \\
\hline 6 & $\begin{array}{l}\text { DQ352762; DQ352761; DQ352760; } \\
\text { DQ352759; DQ352758; DQ352757; } \\
\text { DQ352756; DQ352755; DQ352754; } \\
\text { DQ352753 }\end{array}$ & Amazônica/Peru & Peru & Pearse et al., 2006 \\
\hline 7 & $\begin{array}{l}\text { DQ352752; DQ352751; DQ352750; } \\
\text { DQ352749; DQ352748; DQ352747; } \\
\text { DQ352746; DQ352745; DQ352744; } \\
\text { DQ352743; DQ352742; DQ352741 }\end{array}$ & Amazônica/Brasil & Purus & Pearse et al., 2006 \\
\hline 8 & $\begin{array}{l}\text { DQ352740; DQ352739; DQ352738; } \\
\text { DQ352737; DQ352736; DQ352735; } \\
\text { DQ352734; DQ352733; DQ352732; } \\
\text { DQ352731; DQ352730; DQ352729; } \\
\text { DQ352728; DQ352727; DQ352726; } \\
\text { DQ352725; DQ352724; DQ352723; } \\
\text { DQ352722; DQ352721; DQ352720; } \\
\text { DQ352719 }\end{array}$ & Amazônica/Brasil & Guaporé & Pearse et al., 2006 \\
\hline 9 & $\begin{array}{l}\text { DQ352718; DQ352717; DQ352716; } \\
\text { DQ352715; DQ352714; DQ352713; } \\
\text { DQ352712; DQ352711; DQ352710; } \\
\text { DQ352709; DQ352708; DQ352707; } \\
\text { DQ352706; DQ352705; DQ352704; } \\
\text { DQ352703; DQ352702; DQ352701; } \\
\text { DQ352700; DQ352699; DQ352698; } \\
\text { DQ352697 }\end{array}$ & Amazônica/Brasil & Guaporé/ Pimenteiras & Pearse et al., 2006 \\
\hline 10 & $\begin{array}{l}\text { DQ352696; DQ352695; DQ352694; } \\
\text { DQ352693; DQ352692; DQ352691; } \\
\text { DQ352690; DQ352689; DQ352688; } \\
\text { DQ352687; DQ352686; DQ352685; } \\
\text { DQ352684; DQ352683; DQ352682; } \\
\text { DQ352681; DQ352680; DQ352679 }\end{array}$ & Amazônica/Brasil & Uatumã & Pearse et al., 2006 \\
\hline 11 & $\begin{array}{l}\text { DQ352678; DQ352677; DQ352676; } \\
\text { DQ352675; DQ352674; DQ352673; } \\
\text { DQ352672; DQ352671; DQ352670; } \\
\text { DQ352669; DQ352668; DQ352667; } \\
\text { DQ352666; DQ352665; DQ352664; } \\
\text { DQ352663; DQ352662; DQ352661 }\end{array}$ & Amazônica/Brasil & Amazonas, Terra Santa & Pearse et al., 2006 \\
\hline 12 & $\begin{array}{l}\text { DQ352660; DQ352659; DQ352658; } \\
\text { DQ352657; DQ352656; DQ352655; } \\
\text { DQ352654; DQ352653 }\end{array}$ & Amazônica/Brasil & Trombetas & Pearse et al., 2006 \\
\hline
\end{tabular}




\begin{tabular}{|c|c|c|c|c|}
\hline 13 & $\begin{array}{l}\text { DQ352652; DQ352651; DQ352650; } \\
\text { DQ352649; DQ352648; DQ352647; } \\
\text { DQ352646; DQ352645; DQ352644; } \\
\text { DQ352643; DQ352642; DQ352641; } \\
\text { DQ352640; DQ352639; DQ352638; } \\
\text { DQ352637; DQ352636; DQ352635; } \\
\text { DQ352634; DQ352633; DQ352632 }\end{array}$ & Amazônica/Brasil & Tapajós & Pearse et al., 2006 \\
\hline 14 & $\begin{array}{l}\text { DQ352631; DQ352630; DQ352629; } \\
\text { DQ352628; DQ352627; DQ352626; } \\
\text { DQ352625; DQ352624; DQ352623; } \\
\text { DQ352622; DQ352621; DQ352620; } \\
\text { DQ352619; DQ352618; DQ352617; } \\
\text { DQ352616; DQ352615; DQ352614; } \\
\text { DQ352613; DQ352612; DQ352611; } \\
\text { DQ352610; DQ352609 }\end{array}$ & Amazônica/Brasil & Xingu & Pearse et al., 2006 \\
\hline 15 & $\begin{array}{l}\text { DQ352608; DQ352607; DQ352606; } \\
\text { DQ352605; DQ352604; DQ352603; } \\
\text { DQ352602; DQ352601; DQ352600; } \\
\text { DQ352599; DQ352598; DQ352597; } \\
\text { DQ352596; DQ352595; DQ352594; } \\
\text { DQ352593; DQ352592; DQ352591; } \\
\text { DQ352590; DQ352589 }\end{array}$ & Araguaia/Brasil & Parque Nacional do Araguaia & Pearse et al., 2006 \\
\hline 16 & $\begin{array}{l}\text { DQ352588; DQ352587; DQ352586; } \\
\text { DQ352585; DQ352584; DQ352583; } \\
\text { DQ352582; DQ352581; DQ352580; } \\
\text { DQ352579; DQ352578; DQ352577; } \\
\text { DQ352576; DQ352575; DQ352574; } \\
\text { DQ352573; DQ352572; DQ352571; } \\
\text { DQ352570; DQ352569; DQ352568; } \\
\text { DQ352567 }\end{array}$ & Araguaia/Brasil & Rio das Mortes & Pearse et al., 2006 \\
\hline 17 & $\begin{array}{l}\text { AY572984; AY572983; AY572982; } \\
\text { AF361994; AF361958; AY572985; } \\
\text { AF361976; AF361974; AF361965; } \\
\text { AF361953 }\end{array}$ & $*$ & YN & Pearse et al., 2006 \\
\hline 18 & $\begin{array}{l}\text { AY572981; AF361973; AY572980; } \\
\text { AF361992; AF361990; AF361985; } \\
\text { AF361980; AF361966; AF361952 }\end{array}$ & $*$ & GN & Pearse et al., 2006 \\
\hline 19 & $\begin{array}{l}\text { AY572979; AY572978; AF361963; } \\
\text { AF361984; AF361983; AF361981; } \\
\text { AF361978; AF361959; AF361955 }\end{array}$ & $*$ & $\mathrm{CN}$ & Pearse et al., 2006 \\
\hline 20 & $\begin{array}{l}\text { AF361997; AF361972; AF361989; } \\
\text { AF361988; AF361967 }\end{array}$ & $*$ & G & Pearse et al., 2006 \\
\hline 21 & $\begin{array}{l}\text { AF361996; AF361987; AF361951; } \\
\text { AF361991; AF361977; AF361964; } \\
\text { AF361962; AF361961; AF361956 }\end{array}$ & $*$ & TDT & Pearse et al., 2006 \\
\hline 22 & $\begin{array}{l}\text { AF361975; AF361982; AF361979; } \\
\text { AF361970; AF361960 }\end{array}$ & $*$ & $\mathrm{C}$ & Pearse et al., 2006 \\
\hline 23 & $\begin{array}{l}\text { AF361957; AF361993; AF361969; } \\
\text { AF361968; AF361954 }\end{array}$ & $*$ & Y & Pearse et al., 2006 \\
\hline 24 & AF361995; AF361986; AF361971 & $*$ & TCO & Pearse et al., 2006 \\
\hline 25 & FM165614 & Mar do Caribe & $\begin{array}{l}\text { Bacias de drenagem Magdalena, } \\
\text { Cauca, San Jorge e Sinú }\end{array}$ & $\begin{array}{l}\text { Vargas-Ramirez et } \\
\text { al., } 2008\end{array}$ \\
\hline
\end{tabular}

* Sequências com localização específica não disponíveis no GenBank. 
Quadro 1S - Comparação entre os primers e materiais biológicos utilizados em trabalhos de genética populacional de quelônios do gênero Podocnemis.

\begin{tabular}{|c|c|c|c|c|c|c|c|c|c|}
\hline $\begin{array}{l}\text { Título do } \\
\text { Estudo }\end{array}$ & Espécie & $\begin{array}{c}\text { Número } \\
\text { de pb }\end{array}$ & $\begin{array}{l}\text { Material } \\
\text { biológico }\end{array}$ & $\begin{array}{c}\text { Primer } \\
\text { forward }\end{array}$ & $\begin{array}{l}\text { Sequên- } \\
\text { cia primer } \\
\text { forward }\end{array}$ & Literatura & $\begin{array}{l}\text { Primer } \\
\text { reverse }\end{array}$ & $\begin{array}{c}\text { Sequência } \\
\text { primer reverse }\end{array}$ & Literatura \\
\hline $\begin{array}{l}\text { Presente } \\
\text { estudo }\end{array}$ & P. expansa & 519 & $\begin{array}{l}\text { Tecido } \\
\text { cutâneo }\end{array}$ & $\mathrm{CR} F$ & $\begin{array}{l}\text { 5'- } \\
\text { AACTCCCAT } \\
\text { CACCTACTC } \\
\text { CCAAAG-3' }\end{array}$ & $\begin{array}{l}\text { Presente } \\
\text { estudo }\end{array}$ & CR-R & $\begin{array}{l}5^{\prime}- \\
\text { TGAACCAG } \\
\text { AATGTCCAG } \\
\text { CCTCTCA-3' }\end{array}$ & $\begin{array}{l}\text { Presente } \\
\text { estudo }\end{array}$ \\
\hline $\begin{array}{l}\text { Presente } \\
\text { estudo }\end{array}$ & P. expansa & $\begin{array}{l}\text { Não am- } \\
\text { plificou }\end{array}$ & $\begin{array}{l}\text { Tecido } \\
\text { cutâneo }\end{array}$ & PRO & $\begin{array}{l}\text { 5'- } \\
\text { CCСATCACC } \\
\text { CACTCCCAA } \\
\text { AGC-3' }\end{array}$ & $\begin{array}{l}\text { Pearse et al. } \\
\text { (2006) }\end{array}$ & 12SR5 & $\begin{array}{l}\text { 5'- } \\
\text { GTCAGGACC } \\
\text { ATGCCTTTG } \\
\text { TG-3' }\end{array}$ & $\begin{array}{l}\text { Kocher et al. } \\
\text { (1989) }\end{array}$ \\
\hline \multirow{2}{*}{$\begin{array}{l}\text { Pearse et al. } \\
\text { (2006) }\end{array}$} & \multirow{2}{*}{ P. expansa } & \multirow{2}{*}{1343} & \multirow{2}{*}{$\begin{array}{l}\text { Tecido do } \\
\text { fígado ou } \\
\text { sangue }\end{array}$} & Pro & $\begin{array}{l}5^{\prime}- \\
\text { CCCATCACC } \\
\text { CACTCCCAA } \\
\text { AGC-3' }\end{array}$ & $\begin{array}{l}\text { Pearse et al. } \\
(2006)\end{array}$ & DLR & $\begin{array}{l}\text { 5'- } \\
\text { GGGATGCTG } \\
\text { GTTTCTTGA } \\
\text { G-3' }\end{array}$ & $\begin{array}{l}\text { Pearse et al. } \\
\text { (2006) }\end{array}$ \\
\hline & & & & CSB & $\begin{array}{l}\text { 5- } \\
\text { TTATAGTGCT } \\
\text { CTTCCCCATA } \\
\text { TTATG-3' }\end{array}$ & $\begin{array}{l}\text { Pearse et al. } \\
\text { (2006) }\end{array}$ & PodF & $\begin{array}{l}\text { 5'- } \\
\text { TAATCTATC } \\
\text { GCATCTTCA } \\
\text { G-3' }\end{array}$ & $\begin{array}{l}\text { Pearse et al., } \\
\text { (2006) }\end{array}$ \\
\hline \multirow{2}{*}{$\begin{array}{l}\text { Piñeda- } \\
\text {-Catalán et } \\
\text { al. (2012) }\end{array}$} & \multirow{2}{*}{ P. expansa } & \multirow{2}{*}{1120} & \multirow{2}{*}{$\begin{array}{l}\text { Sangue, } \\
\text { tecido ou } \\
\text { músculo }\end{array}$} & Pro & $\begin{array}{l}\text { 5'- } \\
\text { CССАТСACC } \\
\text { CACTCCCAA } \\
\text { AGC-3' }\end{array}$ & $\begin{array}{l}\text { Pearse et al. } \\
(2006)\end{array}$ & DLR & $\begin{array}{l}\text { 5'- } \\
\text { GGGATGCTG } \\
\text { GTTTCTTGA } \\
\text { G-3' }\end{array}$ & $\begin{array}{l}\text { Pearse et al., } \\
\text { (2006) }\end{array}$ \\
\hline & & & & CSB & $\begin{array}{l}\text { 5- } \\
\text { TTATAGTGCT } \\
\text { CTTCCCCATA } \\
\text { TTATG-3' }\end{array}$ & $\begin{array}{l}\text { Pearse et al. } \\
\text { (2006) }\end{array}$ & PodF & $\begin{array}{l}\text { 5'- } \\
\text { TAATCTATC } \\
\text { GCATCTTCA } \\
\text { G-3' }\end{array}$ & $\begin{array}{l}\text { Pearse et al., } \\
\text { (2006) }\end{array}$ \\
\hline \multirow{2}{*}{$\begin{array}{l}\text { Piñeda- } \\
\text {-Catalán et } \\
\text { al. (2012) }\end{array}$} & \multirow{2}{*}{ P. unifilis } & \multirow{2}{*}{630} & \multirow{2}{*}{$\begin{array}{l}\text { Sangue, } \\
\text { tecido ou } \\
\text { músculo }\end{array}$} & Pro & $\begin{array}{l}5^{\prime}- \\
\text { CCCATCACC } \\
\text { CACTCCCAA } \\
\text { AGC-3' }\end{array}$ & $\begin{array}{l}\text { Pearse et al. } \\
\text { (2006) }\end{array}$ & DLR & $\begin{array}{l}\text { 5'- } \\
\text { GGGATGCTG } \\
\text { GTTTCTTGA } \\
\text { G-3' }\end{array}$ & $\begin{array}{l}\text { Pearse et al., } \\
\text { (2006) }\end{array}$ \\
\hline & & & & $\mathrm{CR} 2 \mathrm{~F}$ & $\begin{array}{l}\text { 5'- } \\
\text { AGCCTTCGT } \\
\text { GGTCCTAGC } \\
\text { GGT-3' }\end{array}$ & $\begin{array}{l}\text { Piñeda- } \\
\text {-Catalán et } \\
\text { al. (2012) }\end{array}$ & CR2R & $\begin{array}{l}\text { 5'- } \\
\text { GGGGTCCG } \\
\text { GGGTGGGA } \\
\text { TCAT-3' }\end{array}$ & $\begin{array}{l}\text { Piñeda- } \\
\text { Catalán et } \\
\text { al. (2012) }\end{array}$ \\
\hline $\begin{array}{l}\text { Agostini } \\
(2016)\end{array}$ & P. unifilis & 508 & Sangue & PRO & $\begin{array}{l}5 '- \\
\text { CССATCACC } \\
\text { CACTCCCAA } \\
\text { AGC-3' }\end{array}$ & $\begin{array}{l}\text { Pearse et al., } \\
(2006)\end{array}$ & 12SR5 & $\begin{array}{l}\text { 5'- } \\
\text { GGCGGATA } \\
\text { CTTGCATGT } \\
-3 \text { ' }\end{array}$ & $\begin{array}{l}\text { Hrbek \& } \\
\text { Farias } \\
(2008)\end{array}$ \\
\hline $\begin{array}{l}\text { Santos et al. } \\
\text { (2016) }\end{array}$ & P. erythrocephala & 550 & Sangue & PRO & $\begin{array}{l}5^{\prime}- \\
\text { CССATCACC } \\
\text { CACTCCCAA } \\
\text { AGC-3' }\end{array}$ & $\begin{array}{l}\text { Pearse et al. } \\
\text { (2006) }\end{array}$ & 12SR5 & $\begin{array}{l}\text { 5'- } \\
\text { GGCGGATA } \\
\text { CTTGCATGT } \\
-3 \text { ' }\end{array}$ & $\begin{array}{l}\text { Hrbek \& } \\
\text { (Farias } \\
\text { 2008) }\end{array}$ \\
\hline $\begin{array}{l}\text { Michels \& } \\
\text { Vargas- } \\
\text { Ramirez } \\
(2018)\end{array}$ & P. erythrocephala & 546 & $\begin{array}{l}\text { Sangue } \\
\text { e tecido } \\
\text { cutâneo }\end{array}$ & CoEryfor & $\begin{array}{l}5^{\prime}- \\
\text { CССАТСACC } \\
\text { TACTCCСAA } \\
\text { AGC-3' }\end{array}$ & $\begin{array}{l}\text { Michels \& } \\
\text { Vargas- } \\
\text {-Ramirez, } \\
(2018)\end{array}$ & CoEryrev & $\begin{array}{l}5^{\prime}- \\
\text { GATTATCCC } \\
\text { CATGAAAG } \\
\text { CAATAAGC- } \\
3^{\prime}\end{array}$ & $\begin{array}{l}\text { Michels } \\
\text { \&Vargas- } \\
\text {-Ramirez } \\
(2018)\end{array}$ \\
\hline $\begin{array}{l}\text { Viana et al., } \\
\text { (2017) }\end{array}$ & P. sextuberculata & 605 & Sangue & DLSex & $\begin{array}{l}\text { 5'- } \\
\text { AGTGCTCTT } \\
\text { CCCCATATTA } \\
\text { TG-3' }\end{array}$ & $\begin{array}{l}\text { Viana et al. } \\
\text { (2017) }\end{array}$ & 12SR5 & $\begin{array}{l}\text { 5'- } \\
\text { GTCAGGACC } \\
\text { ATGCCTTTG } \\
\text { TG-3' }\end{array}$ & $\begin{array}{l}\text { Kocher et al. } \\
\text { (1989) }\end{array}$ \\
\hline $\begin{array}{l}\text { Vargas-Rami- } \\
\text { rez (2012) }\end{array}$ & P. lewyana & 691 & Sangue & LewDLFor1 & $\begin{array}{l}5^{\prime}- \\
\text { TAAGTCTAG } \\
\text { GAGAGTTTA } \\
\text { CGCG-3' }\end{array}$ & $\begin{array}{l}\text { Vargas- } \\
\text {-Ramirez } \\
(2012)\end{array}$ & $\begin{array}{l}\text { LewDL- } \\
\text { Rev1 }\end{array}$ & $\begin{array}{l}5^{\prime}- \\
\text { GGTAGATCA } \\
\text { TCTCCAATT } \\
\text { ACGG-3' }\end{array}$ & $\begin{array}{l}\text { Vargas-Ra- } \\
\text { mirez (2012) }\end{array}$ \\
\hline
\end{tabular}


Biodiversidade Brasileira - BioBrasil.

Edição Temática: PIBIC

n. 1,2022

http://www.icmbio.gov.br/revistaeletronica/index.php/BioBR

Biodiversidade Brasileira é uma publicação eletrônica científica do Instituto Chico Mendes de

Conservação da Biodiversidade (ICMBio) que tem como objetivo fomentar a discussão e a disseminação de experiências em conservação e manejo, com foco em unidades de conservação $e$ espécies ameaçadas.

ISSN: 2236-2886 